\title{
Novel UWB Monopole Antenna With Band Notched Characteristics
}

\author{
V.N.Koteswara Rao. Devana ${ }^{1}$,B.S.L.Mounika ${ }^{2}$, B.Yamini ${ }^{2}$, G.Anitha ${ }^{2}$ and \\ G.BalaSaiTarun ${ }^{2}$ \\ ${ }^{1}$ Assistant Professor, SACET, Chirala, AP, India \\ ${ }^{2}$ Students of Dept. of ECE, SACET, Chirala, AP, India \\ 'dvnkrao@gmail.com
}

\begin{abstract}
A compact planar monopole antenna with band-notched characteristics suitable for Ultra Wideband (UWB) applications is presented. The proposed UWB microstrip-fed antenna consisting of $U$-shaped slots in both patch and the microstrip-feed line with a defected ground structure. This antenna is designed to cover the Federal Communication Commission (FCC) bandwidth for UWB applications (2.04-14.6 GHz), while showing tri band-notched characteristics in the frequency bands of: $(3-4.3 \mathrm{GHz})$ used for WiMAX, (6.12-6.8 GHz) used for C-band uplink frequency and (8.7-9.2 GHz) used for aeronautical radio navigation. The proposed antenna is suitable for various narrow band wireless applications, satellite applications and radar applications. The proposed UWB antenna is simulated by using High Frequency Structural Simulator (HFSS).
\end{abstract}

Keywords: Ultra Wideband (UWB) antenna, slots, Band-notched characteristics, HFSS

\section{Introduction}

Due to the rapid growth in wireless communication systems, a huge demand for wide band antennas to satisfy high gain and large bandwidth covering all frequency ranges. UWB technology was released in February 2002 by FCC, to cover the frequency band (3.1-10.6) $\mathrm{GHz}$ [1]. UWB systems have been allocated for the merits of high transmission rate, high capacity, and low power consumption for indoor communication applications. Printed monopole antennas are good candidates for UWB communication because of its ease of fabrication, simple structure, low profile and lightweight. Over the designated bandwidth of UWB system, there are some other existing narrowband services that already occupy frequencies in the UWB band, such as World interoperability for Microwave Access (WiMAX) IEEE802.16 operating in the 3.3 to $3.7 \mathrm{GHz}$ frequency range, $\mathrm{C}$ band satellite communication in the 3.7 to $4.2 \mathrm{GHz}$ frequency range and Wireless Local Area Network (WLAN) IEEE802.11aand High Performance Local Area

Networks (HIPERLAN/2) operating in the 5.15-5.825 GHz frequency range. In some applications, UWB antenna uses filters to suppress dispensable bands. However, the uses of filters increase the complexity of the UWB system and lead to increase in cost. Hence, it is desirable to design the UWB antenna with notched frequency bands to minimize the potential interferences between UWB system and narrowband systems. These UWB antennas with filtering property have been proposed not only to diminish the potential interferences but also to remove the requirement of an extra band-stop filter in the system [2]. Recently, more and more band-notched UWB antenna designs have been proposed. In this paper, we propose a low cost and Novel UWB Monopole Antenna With Band Notched Characteristics The tri band-notched operations are achieved by introducing one $\mathrm{U}$-slot in the patch, another $\mathrm{U}$-slot in the feed line and with defected ground structure. The U-slot in the patch reject the frequency bands (3.04-4.31) GHz used for WiMAX and 
(8.7-9.2) GHz used for aeronautical radio navigation. The another U-slot in the feed line will reject the (6.12-6.8) GHz for c-band uplink frequency.

\section{Antenna Design}

The main drawback in designing a UWB antenna is interference due to existed wireless systems. Hence the present work is focus on to eliminate the interference. However, different studies focused on enhancing the BW using different techniques such as embedding a semielliptical fractal complementary slots in the ground plane for an egg shaped antenna [3]. Other means such as inserting an inverted T-shaped slot in the patch and T-shape conductor at the back side of the patch [4]. Other studies focused on creating band rejection to the systems that overlap with the UWB frequency range and cause interference to it such as WLAN and X-band systems by adding band stop filter around these bands. To avoid adding new circuits to the communication system, band-notching technique can be applied directly to various UWB planar antennas by loading the UWB antenna with resonant slots at the center frequency of the stop band.

The structure of the proposed antenna is shown in Figure 1. The dimensions of the geometry are given in the Table 1. For better performance, a thick dielectric substrate having a low dielectric constant is desirable as it provides better efficiency, larger bandwidth and better radiation. Here, the substrate selected for the design of the proposed antenna is FR4_epoxy and with permittivity $\left(\varepsilon_{\mathrm{r}}=4.4\right)$.

Table 1.Dimensions of the Proposed Antenna

\begin{tabular}{|l|l|l|l|l|l|l|l|l|l|l|l|}
\hline parameter & Wp & W1 & W2 & W3 & W4 & Wf & W5 & W6 & W7 & W8 & Lg \\
\hline Value $(\mathbf{m m})$ & 15.0 & 1.25 & 1.75 & 1.25 & 0.75 & 2.85 & 1.5 & 12 & 2.0 & 3.0 & 12.5 \\
\hline Parameter & Lp & L1 & L2 & L3 & L4 & Lf & L5 & L6 & L7 & L8 & L9 \\
\hline Value(mm) & 14.5 & 0.75 & 1.25 & 1.0 & 2.0 & 13.5 & 11.0 & 9.0 & 5.62 & 1.25 & 2.0 \\
\hline
\end{tabular}

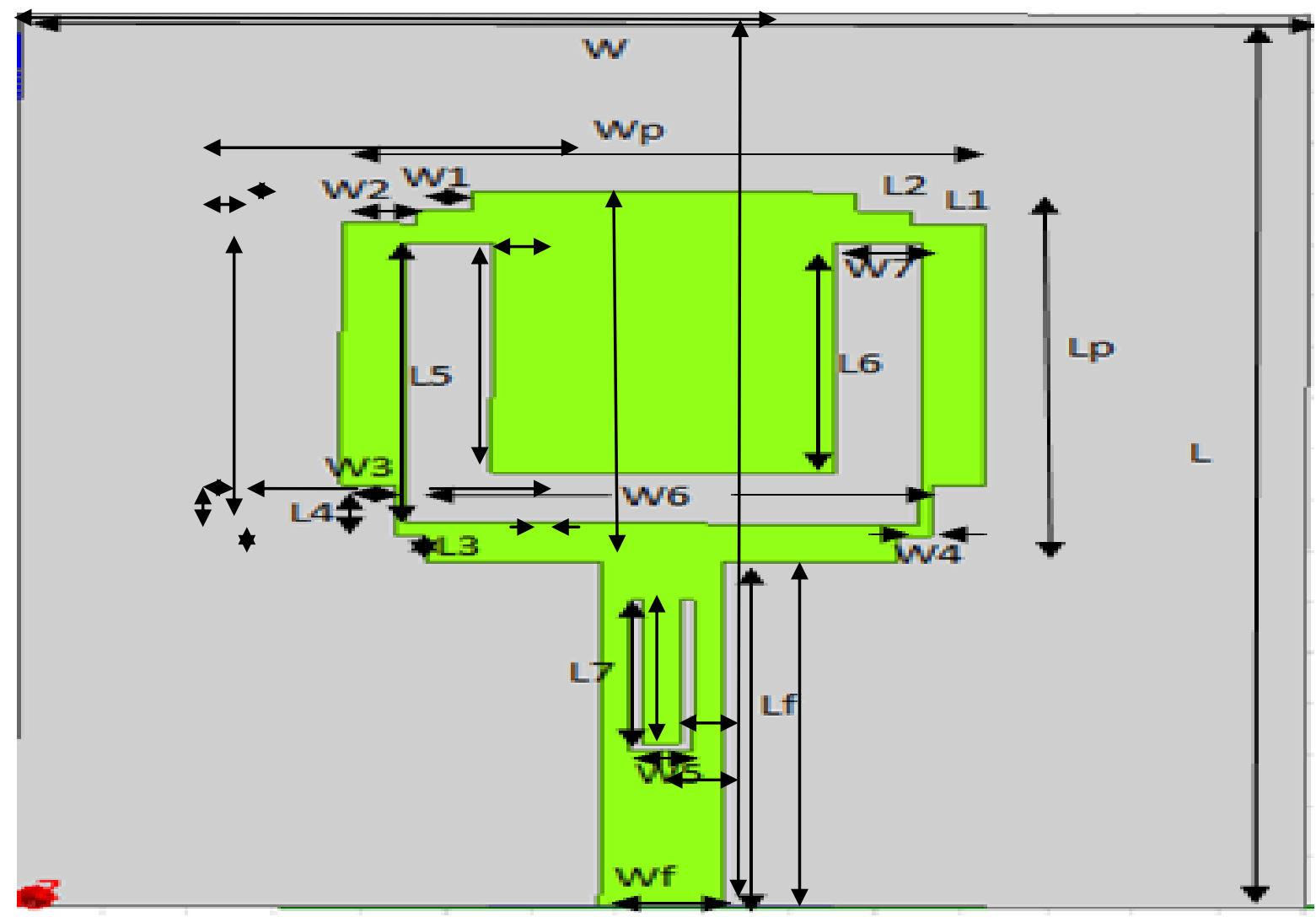




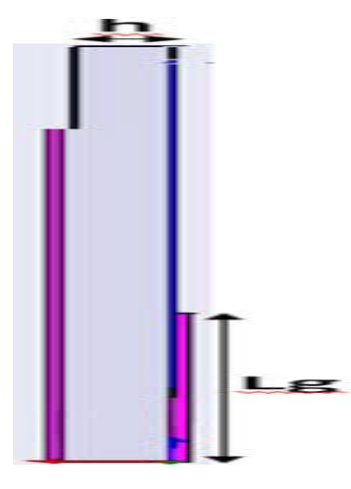

Side View

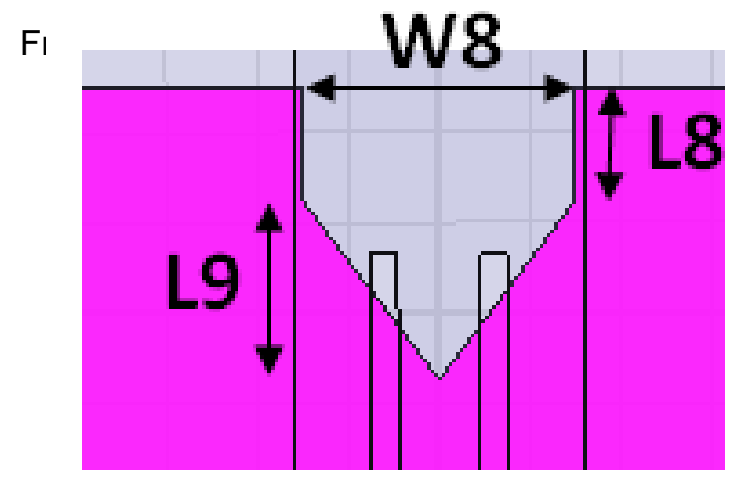

Back view

Figure 1. Geometry of the Proposed Antenna

The dimensions of the substrate are taken as $30 \times 35 \times 1.6 \mathrm{~mm}^{3}$. The proposed antenna is simulated by using microstrip feeding. The width of the U-slot in the feed line is $0.3 \mathrm{~mm}$.

\section{Simulation Results}

The proposed UWB antenna is simulated with an EM simulator, High Frequency Structural Simulator (HFSS). The plot of the simulated return loss of the proposed antenna is shown in Figure 2. From the plot, it is observed that the proposed antenna has a wide bandwidth ranging form $2.04 \mathrm{GHz}$ to $14.06 \mathrm{GHz}$ with tri band notched characteristics are in the frequency bands of $(3-4.3 \mathrm{GHz})$ used for WiMAX, (6.12-6.8 GHz) used for C-band uplink frequency and (8.7-9.2 GHz) used for aeronautical radio navigation. The VSWR plot for the proposed antenna is shown in Figure 3, which gives the desired value of VSWR $<2$ over the UWB frequency range. A good Omnidirectional radiation pattern of the proposed antenna in E-plane and H-plane are shown in Figure 4.

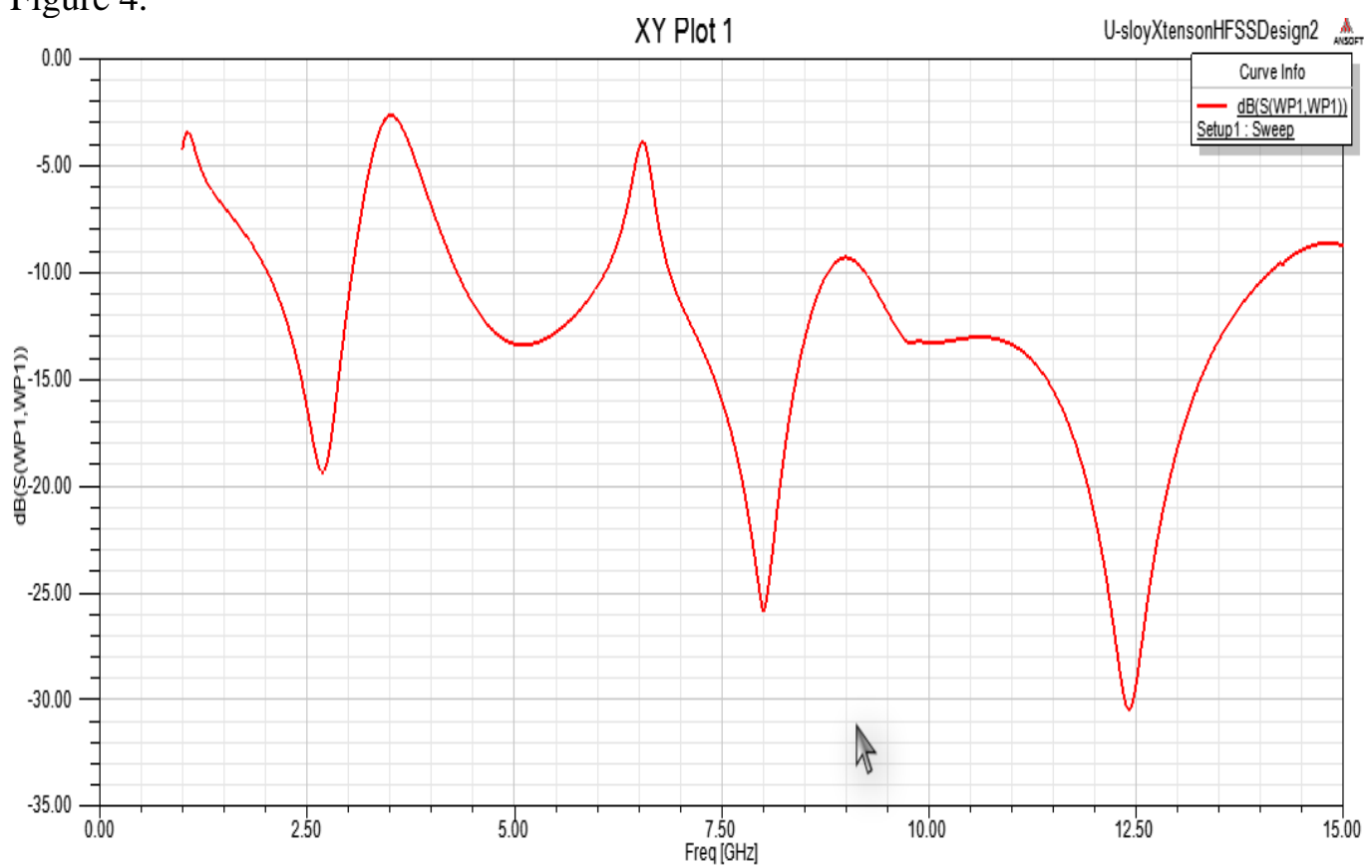

Figure 2. Return Loss Plot of the Proposed UWB Antenna with Band Notching Characteristics 


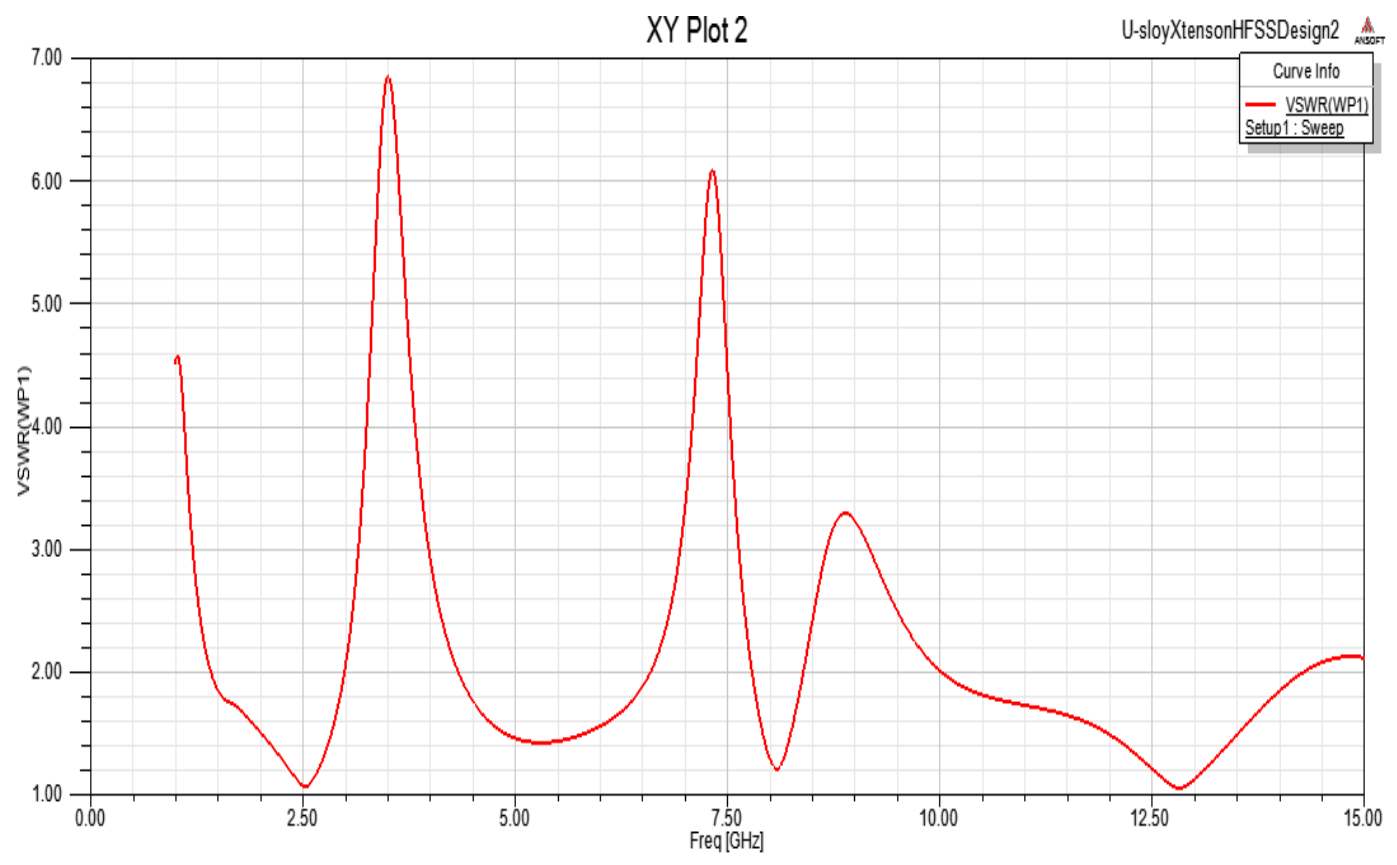

Figure 3. VSWR Plot of the Proposed UWB Antenna with Band Notching Characteristics

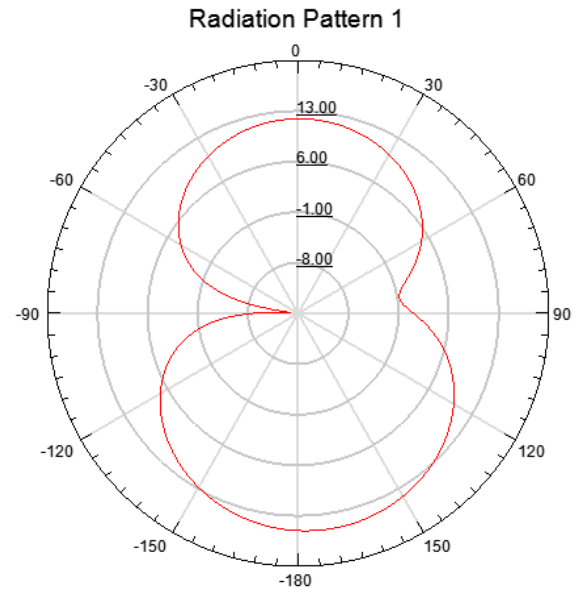

a)

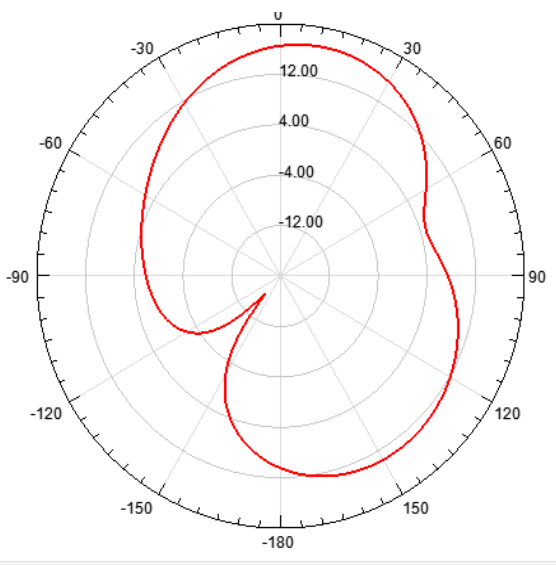

b)

Figure 4. Radiation Pattern of the Proposed UWB Antenna at a) $2.63 \mathrm{GHz}$ b)

\section{$7.96 \mathrm{GHz}$}

\section{Conclusion and Future Scope}

In this paper, UWB antenna with band notched characteristics is simulated and presented. By etching $\mathrm{U}$-shaped slots in the radiating patch and in the microstrip feed line, a triple band notched characteristics in UWB frequency range are obtained. The proposed antenna can be used for UWB applications since it has a bandwidth ranging from 2.0414.6 GHz with a stable radiation pattern and shows notched characteristics in the frequency bands of 3-4.3 GHz, 6.12-6.8 GHz and 8.7-9.2 GHz. In future, this work can be extended by notching other bands presented in UWB in order to reduce the interference due to existing of several narrow band wireless standards. 


\section{References}

[1] N. M.Awad and Mohamed K. Abdelazeez, "New UWB Antenna with Inverted F and U Shape Slots to Reject WLAN and X-Band Applications", IEEE GCC Conferenceand exhibition, Doha, Qatar, (2013) November 17-20,

[2] S. K. Mishra and J. Mukherjee, "Compact Printed Dual Band-Notched U-Shape UWB Antenna",Progress In Electromagnetics Research C, vol. 27, (2012), pp. 169-181,.

[3] K.-R. Chen, Ch.-Y.-D Sim and J.-Sh. Row, "A Compact Monopole Antenna for Super Wideband Applications, IEEE Antennasand Wireless Propagation Letters, vol. 10, (2011), pp.1536-1225.

[4] Yazdanifard, S. Ojaroudi, M. Ojaroudi, N. and M Naser-Moghaddasi, "Small Square Monopole Antenna with Enhanced Bandwidth by using Inverted T-Shaped Slot and Conductor-Backed Plane", IEEE Transactions on Antennas and Propagation, vol. 59, no. 2, (2011) February.

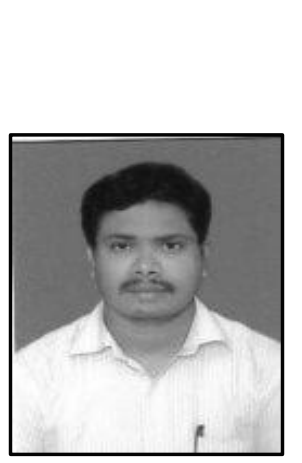

\section{Authors}

V.N. KoteswaraRao. Devana, received his B.Tech. Degree in Electronics and Communication Engineering in 2004 from V.R.Siddhartha Engineering College, ANU, Guntur, India and M.Tech.Degree in Systems \& Signal Processing from JNTU Hyderabad, India in 2011. Presently working Assistant prof. at SACET, JNTU Kakinada. His research interests include Microstrip Antennas, UWB antennas and Wireless communications. As of today, he has published thirteen (13) research papers in various international journals and conferences.

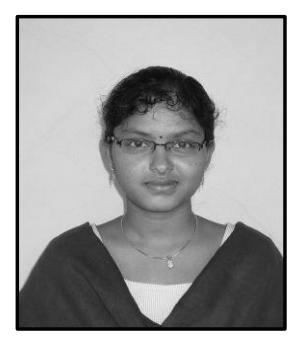

B.S.L.Mounika pursuing B.Tech degree in Electronics and Communication Engineering in 2016 from the JNTU University, Kakinada. Her areas of interest include Microstrip Antennas, UWB Antennas, and Wireless communications.

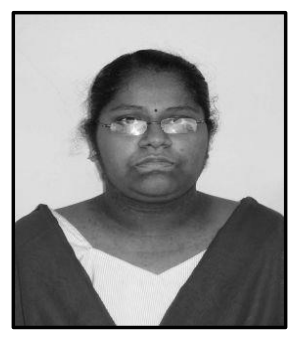

B.Yamini pursuing B.Tech degree in Electronics and Communication Engineering in 2016 from the JNTU University, Kakinada. Her areas of interest include Microstrip Antennas, UWB Antennas, and Wireless communications.

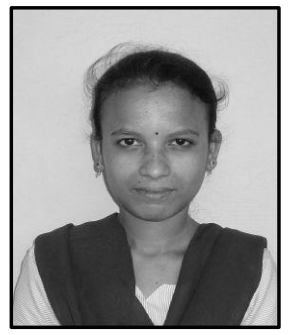

G.Anitha pursuing B.Tech degree in Electronics and Communication Engineering in 2016 from the JNTU University, Kakinada. Her areas of interest include Microstrip Antennas, UWB Antennas, and Wireless communications.

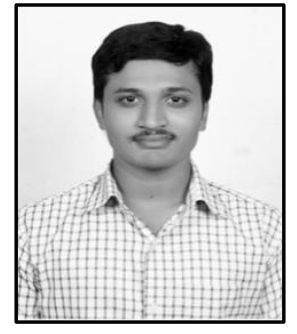

G.BalaSaiTarun pursuing B.Tech degree in Electronics and Communication Engineering in 2016 from the JNTU University, Kakinada. His areas of interest include Microstrip Antennas, UWB Antennas, and Wireless communications. 
International Journal of Signal Processing, Image Processing and Pattern Recognition Vol. 9, No. 5 (2016) 